\title{
Commissural dehiscence: A rare and peculiar cause of porcine valve structural deterioration
}

\author{
Tomaso Bottio, MD, PhD, ${ }^{a}$ Marialuisa Valente, MD, ${ }^{b}$ Giulio Rizzoli, MD, ${ }^{a}$ Vincenzo Tarzia, MD, ${ }^{\text {a }}$ Gianluigi Bisleri, $M D,{ }^{a}$
} Elena Pettenazzo, BSc, PhD, ${ }^{\mathrm{b}}$ Gino Gerosa, MD, and Gaetano Thiene, MD, FRCP ${ }^{\mathrm{b}}$

Objective: Calcification is the main cause of structural valve deterioration; however, other causes of failure have been identified, and among them, dehiscence of a commissure from the stent has been reported in several models of porcine valves. The aim of this study was to analyze the rate and mode of occurrence of this complication in first- and second-generation porcine bioprosthetic explants.

Methods: Among 586 porcine xenografts explanted and analyzed at the Institute of Pathological Anatomy of the University of Padua, 17 (2.9\%) have been replaced for incompetence because of commissural dehiscence. All these explants were in the mitral position, with the exception of a Carpentier-Edwards supra-annular aortic valve prosthesis.

Results: Dehiscence was observed in $9(1.9 \%)$ of 455 Hancock standard explants, in $1(3.2 \%)$ of 31 Hancock II, in 3 (8.6\%, 2 standard and 1 supra-annular) of 35 Carpentier-Edwards, in 1 (2.4\%) of 42 Bioimplants, and in $3(50 \%)$ of 6 Xenotech after a mean time function of $157 \pm 50,156,96 \pm 29,143$, and $130 \pm 8$ months, respectively. Dehiscence was the sole cause of incompetence in 6 cases. An impending commissural dehiscence caused by blood creeping was observed in one case. This might be an explanation for the dehiscence other than excessive trimming of the aortic wall.

Conclusions: Commissural dehiscence is an uncommon and peculiar mode of failure of porcine valves implanted in the mitral position and was observed earlier and more frequently with Carpentier-Edwards porcine explants $(P<.05)$. We speculate that pericardial strip protection of the suture between the Dacron fabric and porcine aortic wall, as used in the Biocor porcine valve, might prevent this complication.

From the Departments of Cardiovascular Surgery $^{\mathrm{a}}$ and Pathology, ${ }^{\mathrm{b}}$ University of Padua Medical School, Padua, Italy.

Supported by grants from Istituto Superiore di Sanità and Ministero Istruzione Università e Ricerca, Rome, Italy, and by Regione Veneto, Venice, Italy.

Received for publication Feb 2, 2006; revisions received May 23, 2006; accepted for publication June 7, 2006

Address for reprints: Tomaso Bottio, MD, $\mathrm{PhD}$, Department of Cardiovascular Surgery, Piazza Spedali Civili 1, 25100, Brescia, Italy (E-mail: bottio@med.unibs.it).

J Thorac Cardiovasc Surg 2006;132:1017-22 $0022-5223 / \$ 32.00$

Copyright $(\odot) 2006$ by The American Association for Thoracic Surgery

doi:10.1016/j.jtcvs.2006.06.012
$\mathrm{T}$ issue valve xenografts have been implanted for more than 40 years, and different generations of porcine bioprostheses have been available. The first generation failed mostly because of calcification and suboptimal valve design. Then several improvements, such as supra-annular configuration, stent flexibility, low-pressure glutaraldehyde fixation, strut height reduction, new methods of tissue preservation, and calcium retardant agents, have been introduced, ${ }^{1-3}$ thus enhancing their function and retarding structural valve deterioration (SVD). However, manufacturing factors have seldom been implicated as a direct cause of SVD. The dehiscence of a commissure, namely the commissural detachment of the porcine aortic wall from the stent post, leading to a cusp prolapse and regurgitation, has been reported in first-generation (Carpentier-Edwards standard and Hancock standard) ${ }^{4,5}$ and second-generation (Carpentier-Edwards supra-annular, Medtronic Intact, and Hancock II) porcine valves. ${ }^{1,6,7}$

By using an implant retrieval analysis of all types of bioprostheses implanted at the University of Padua, we investigated the occurrence of commissural dehiscence as a cause of valve incompetence in various valve explants. 


\section{Abbreviations and Acronyms}

SVD $=$ structural valve deterioration

\section{Materials and Methods}

Between January 1970 and January 2004, 2212 patients underwent heart valve replacement with valve xenografts. The majority of the tissue valves used were porcine bioprostheses (1676 porcine vs 536 pericardial). Concerning the porcine valves in the aortic position, the distribution was as follows: $39 \%$ Hancock valves (19702000), 47\% Biocor valves (1990-2005), and 4\% Carpentier-Edwards standard and supra-annular valves (1980-1990), and the remaining were other models, such as Labcor, SJM X-cell, Bioimplant, and Xenotech valves. On the contrary, in the mitral position the distribution was as follows: 68\% Hancock valves (1970-2000), 18\% Biocor (1990-2005), and 8\% Carpentier-Edwards standard and supra-annular (1980-1990), and the remaining were other models, such as Bioimplant, Xenotech, Labcor, and Angell-Shiley valves. The mean age of the patients at the time of the operation was $65 \pm$ 10 years, and $54 \%$ were female. Five hundred eighty-six porcine bioprostheses have been explanted at reoperation and retained for pathologic study. The protocol of the investigation consisted of gross examination, photography of the specimens with a stereoscope, and radiography for a semiquantitative analysis of $\mathrm{Ca}^{++}$ deposits using a 0 - to 4 -point scale, as previously reported. ${ }^{8}$ All the valves were examined in each case at the time of explantation by the same pathologist (GT) with long-term experience in this field, who was skilled enough to rule out surgical manipulations. Each valve was sent to the pathologist with an attached surgical report. There were 538 first-generation porcine bioprostheses (455 Hancock standard, 35 Carpentier-Edwards [26 standard and 9 supra-annular], 42 Bioimplant, and 6 Xenotech) and 48 second-generation porcine bioprostheses (31 Hancock II and 17 Biocor). Details are summarized in Table 1. Four hundred thirty-six were mitral, 136 were aortic, and 14 were tricuspid bioprostheses. Four hundred eighty prostheses were in place for less than 15 years, and the remaining 106 were in place for more than 15 years.

In the entire series of explants, 17 (2.9\%) bioprostheses have been replaced for incompetence because of a peculiar type of SVD, namely commissural dehiscence.

The incidence of commissural dehiscence in the aortic and mitral position and among different valve models was compared by using the Fisher exact test.

\section{Results}

Sixteen bioprostheses with a dehiscent commissure were explanted from the mitral position (28-33 $\mathrm{mm}$ range of label size), and only 1 (Carpentier-Edwards supra-annular) was explanted from the aortic position $(23 \mathrm{~mm} ; P<.005)$. Twelve were implanted in female subjects (mean age, $65.5 \pm 10$ years), and 5 were implanted in male subjects (mean age, $63.8 \pm 6$ years).

\section{Macroscopic Examination}

The commissural dehiscence rate is reported in Table 1, and it was significantly more frequent in Carpentier-Edwards and Xenotech prostheses $(P<.05)$. Commissural dehiscence, with (4 cases) or without ( 2 cases) calcification, was the sole cause of dysfunction in 6 cases after a mean period of function of $187 \pm 62$ months (Figures 1 and 2). In the remaining 11 explants, tears and wears were concomitantly present (mean time of function, $159 \pm 35$ months), with (8 cases) or without (3 cases) calcification. Dehiscence occurred at the anterior commissure (ie, between the right and left cusps) in 13 explants (Table 2).

In 2 prostheses (1 Hancock standard and 1 Xenotech) dehiscence was concomitantly present in 2 different commissural posts; in the Xenotech valve the dehiscence of the anterior commissure was associated with a hematoma of the left posterior commissure, with evidence of incipient detachment (Figure 3).

\section{Time of Function of Different Prosthesis Models}

Commissural detachment of the aortic wall occurred after a mean time of $157 \pm 50$ months in Hancock standard explants, 156 months in Hancock II explants, $96 \pm 29$ months in Carpentier-Edwards (standard and supra-annular) explants, 143 months in the Bioimplant, and $130 \pm 8$ months in the Xenotech. Therefore commissural dehiscence occurred earlier in the Carpentier-Edwards prostheses than in others $(P<.05)$. Of the 3 Carpentier-Edwards prostheses, 2 were standard models implanted in the mitral position in 1980 and 1984, and one was a supra-annular model implanted in the aortic position in 1986.

TABLE 1. Explanted bioprostheses

\begin{tabular}{|c|c|c|c|c|c|c|}
\hline Model & No. & Aortic & Mitral & Tricuspid & Dehiscence rate* & $P$ value \\
\hline Hancock standard & 455 & $104(106 \pm 50)$ & $338(125 \pm 52)$ & $13(143 \pm 49)$ & $9 / 455,2 \%(157 \pm 50)$ & NS \\
\hline Hancock II & 31 & $6(118 \pm 56)$ & $24(101 \pm 54.5)$ & $1(126)$ & $1 / 31,3.2 \%(156)$ & NS \\
\hline Carpentier-Edwards & 35 & $15(122 \pm 50)$ & $20(117 \pm 50)$ & 0 & $3 / 35,8.6 \%(96 \pm 29)$ & $<.05$ \\
\hline Bioimplant & 42 & $3(60 \pm 35)$ & $39(96.4 \pm 31.4)$ & 0 & $1 / 42,2.4 \%(143)$ & NS \\
\hline Xenotech & 6 & 0 & $6(113 \pm 36.5)$ & 0 & $3 / 6,50 \%(130 \pm 80)$ & $<.05$ \\
\hline Biocor & 17 & $8(10 \pm 5)$ & $9(16 \pm 7)$ & 0 & $0 / 17,0 \%$ & - \\
\hline Total & 586 & 136 & 436 & 14 & $17(2.9 \%)$ & \\
\hline
\end{tabular}

Time of function in months is shown in parentheses. *All mitral cases with the exception of 1 Carpentier-Edwards supra-annular valve aortic prosthesis. 


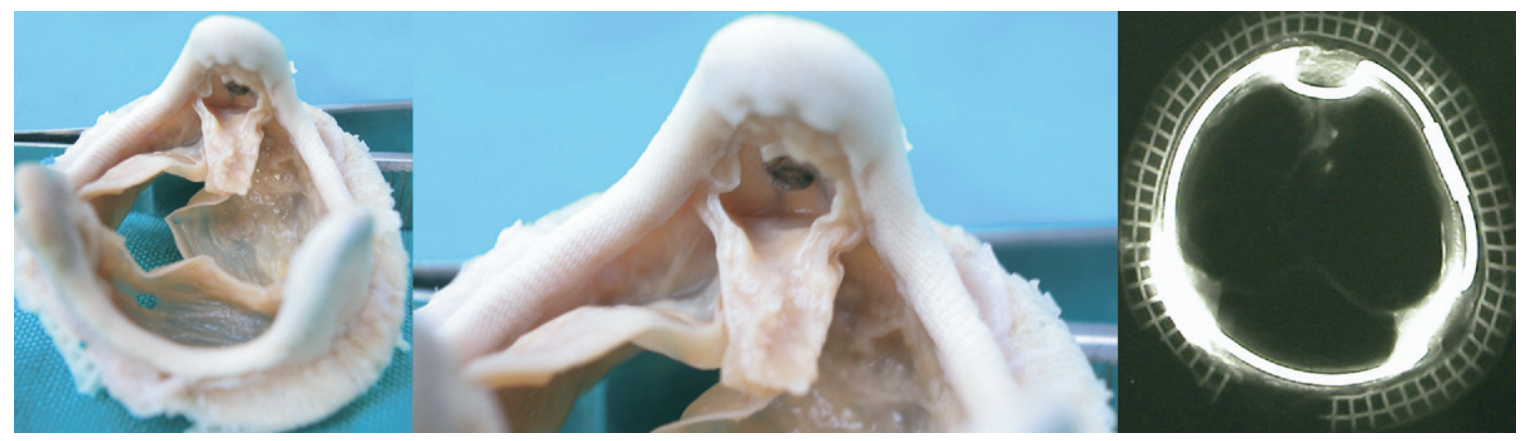

Figure 1. Dehiscence at the anterior commissure in a mitral Carpentier-Edwards standard prosthesis in place for 102 months in the absence of calcification.

\section{Radiographic Findings}

Two prostheses showed no signs of calcification (score 0 at radiography) after 102 months (Carpentier-Edwards standard, Figure 1) and 160 months (Hancock standard), respectively. Eleven prostheses showed initial signs of commissural mineralization (score, 1-2) at a mean time of $163 \pm 50$ months (range, 106-260 months). Four tissue valves showed heavy mineralization at a mean time of $151 \pm 71$ months (score, 3-4; Figure 4).

\section{Discussion}

Among 586 porcine bioprostheses explanted at reoperation at our institute, 496 (85\%) have been replaced as a result of SVD, mostly because of dystrophic calcification. ${ }^{9}$ Seventeen porcine valve xenografts failed because of a detachment of the porcine aortic wall from the stent at the top of the commissural post, so-called commissural dehiscence. ${ }^{4}$

SVD has been extensively documented as the major complication of porcine bioprostheses. ${ }^{7,8}$ However, it has seldom been attributed to a specific manufacturing cause. Nistal and coworkers ${ }^{4}$ first ascribed the cause of commissural dehiscence of Carpentier-Edwards porcine valve models to a manufacturing flaw. According to their results, the commissural dehiscence occurred frequently in those models because of an excessive trimming of the outer layers of the porcine aortic wall accomplished to favor the hemodynamic performance. This manufacturing improvement was introduced in 1986 in the large mitral prostheses, and in 1987, this practice was extended to all sizes of mitral and aortic prostheses. ${ }^{10}$ Moreover, the major stress sustained in the mitral position was an additional risk factor explaining the higher incidence of commissural dehiscence in mitral bioprostheses. ${ }^{4,11}$ Also, in the experience of Jamieson and colleagues, ${ }^{1}$ commissural dehiscence occurred mostly in mitral prostheses, namely 29 (14\%) of 205 explants and only 1 case in the aortic position (1/81 [1.2\%] explants). The average time of function of the affected mitral prostheses was 102.9 months (range, 44.7-162.7 months), whereas commissural dehiscence occurred as late as 172 months in the single affected aortic bioprosthesis. In their series 28 of 29 mitral prostheses were second-generation CarpentierEdwards porcine valves implanted between 1982 and 1986. Concerning position and timing, our results are very similar to those reported by Jamieson and colleagues. ${ }^{1}$ These authors, as well as Kimura and associ-

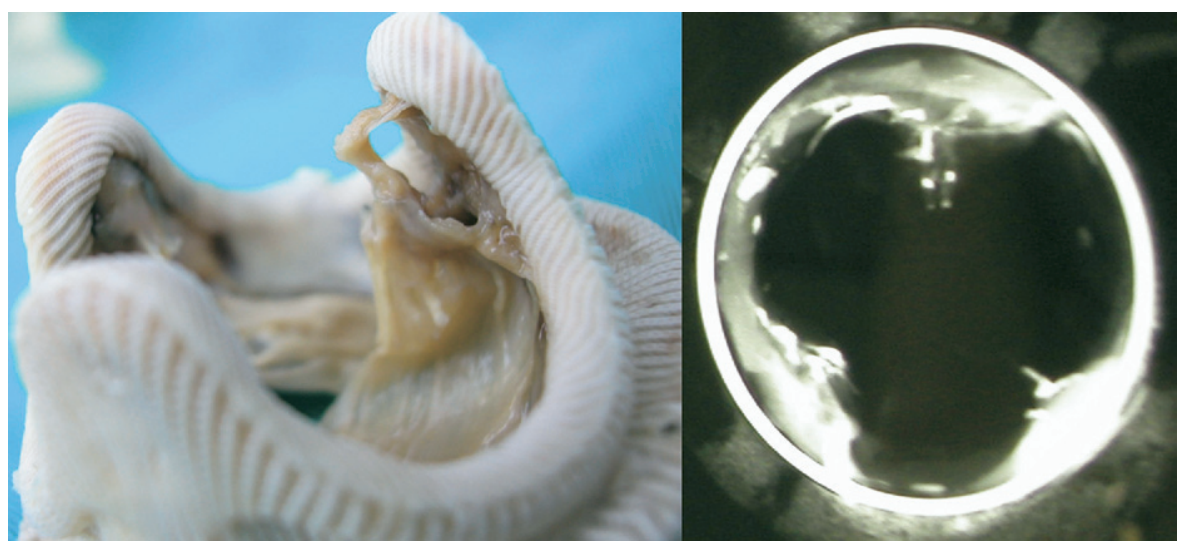

Figure 2. Dehiscence at the anterior commissure in a mitral Hancock standard prosthesis in place for 225 months. Mild calcific deposits were seen at radiography. 
TABLE 2. Porcine bioprostheses with commissural dehiscence

\begin{tabular}{llccl}
\hline Model/ID & Position & Months* & Radiography score & Site of commissural dehiscence \\
\hline Hancock S. $29 \mathrm{~mm}$ & Mitral & 141 & 3 & Anterior commissural dehiscence \\
Hancock S. $29 \mathrm{~mm}$ & Mitral & 160 & 0 & $\begin{array}{c}\text { Double commissural dehiscence } \\
\text { (anterior and left posterior) }\end{array}$ \\
Hancock S. $29 \mathrm{~mm}$ & Mitral & 216 & 2 & Anterior commissural dehiscence \\
Hancock S. $31 \mathrm{~mm}$ & Mitral & 106 & 1 & Anterior commissural dehiscence \\
Hancock S. $29 \mathrm{~mm}$ & Mitral & 172 & 1 & Anterior commissural dehiscence \\
Hancock S. $31 \mathrm{~mm}$ & Mitral & 260 & 2 & Left posterior commissural dehiscence \\
Hancock S. $31 \mathrm{~mm}$ & Mitral & 236 & 4 & Anterior commissural dehiscence \\
Hancock S. $31 \mathrm{~mm}$ & Mitral & 164 & 3 & Right posterior commissural dehiscence \\
Hancock S. $33 \mathrm{~mm}$ & Mitral & 225 & 2 & Anterior commissural dehiscence \\
Hancock II $29 \mathrm{~mm}$ & Mitral & 156 & 2 & Left posterior commissural dehiscence \\
Carpentier-Edwards standard 29 mm & Mitral & 102 & 0 & Anterior commissural dehiscence \\
Carpentier-Edwards standard $31 \mathrm{~mm}$ & Mitral & 64 & 3 & Left posterior commissural dehiscence \\
Carpentier-Edwards SAV $23 \mathrm{~mm}$ & Aortic & 122 & 1 & Anterior commissural dehiscence \\
Xenotech $29 \mathrm{~mm}$ & Mitral & 138 & 1 & Anterior commissural dehiscence \\
Xenotech $31 \mathrm{~mm}$ & Mitral & 132 & 2 & Double commissural dehiscence (anterior and left \\
& & & & posterior), the latter with swelling hematoma \\
Xenotech $33 \mathrm{~mm}$ & Mitral & 122 & 1 & Anterior commissural dehiscence \\
Bioimplant $28 \mathrm{~mm}$ & Mitral & 143 & 1 & Anterior commissural dehiscence
\end{tabular}

SAV, supraannular valve. *Time of function.

ates, ${ }^{12}$ concluded that the modifications introduced in the second-generation Carpentier-Edwards supra-annular model did not improve the durability over the firstgeneration standard valve. The Vancouver group recently reported follow-up to 18 years of the Carpentier-Edwards supra-annular porcine valve in the mitral position and found that commissural dehiscence accounted for $19 \%$ of incompetence (39 of 204 explants with incompetence). ${ }^{13}$

However, this complication was not unique to the Carpentier-Edwards porcine valve because it has been observed also in other second-generation porcine bioprostheses, such as the Hancock $\mathrm{II}^{7}$ and the Medtronic Intact. ${ }^{6,14}$ In these valves aortic wall trimming was not performed, casting doubt on the offered explanation. The Hancock II porcine bioprosthesis was introduced in 1982, with some modifica- tions aimed to improve durability over the Hancock standard bioprosthesis, and such improvements have been confirmed in clinical and pathologic studies. ${ }^{2,3,7,15,16}$ Among 31 Hancock II bioprostheses explanted (our series), a commissural dehiscence not related to calcification or infection was the cause of incompetence in a mitral prosthesis at 156 months after implantation.

Our data confirm the higher incidence of cusp dehiscence in the mitral prostheses, and in agreement with the echocardiographic study of Naqvi and coworkers, ${ }^{17}$ the commissure mostly affected was the anterior commissure, the one that probably supports the higher stress. Only twice have 2 commissures appeared detached, which means that a single dehiscent commissure with double-cusp prolapse might cause a significant valve incompetence requiring valve re-

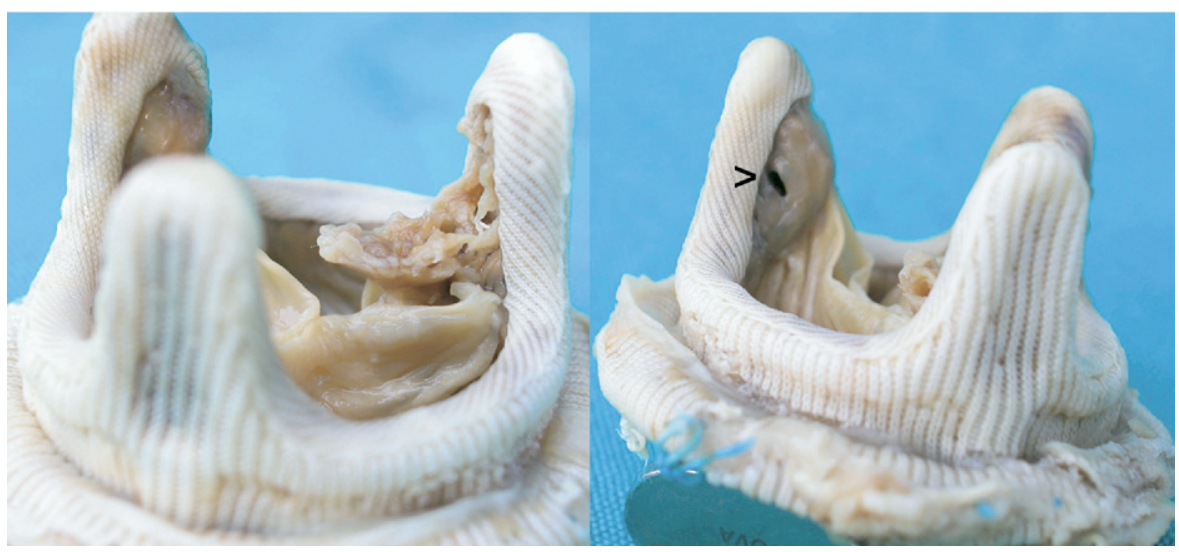

Figure 3. Double commissural dehiscence in a Xenotech mitral valve: one overt and one impending with a hematoma (arrow). 


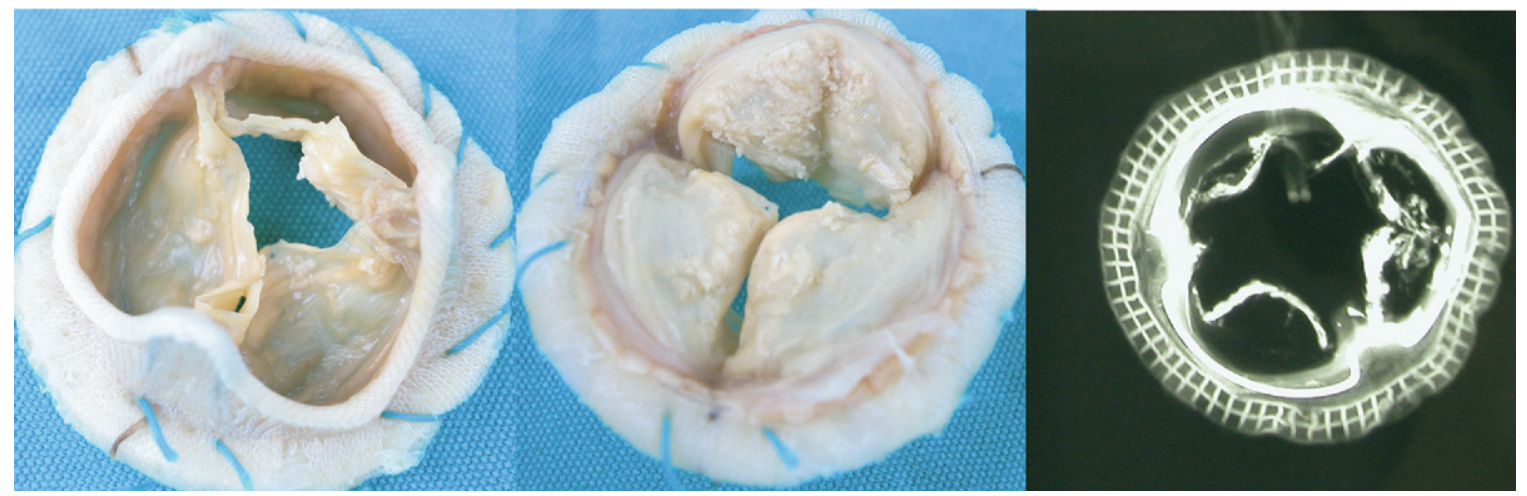

Figure 4. Commissural dehiscence and heavy mineralization with tears in a mitral Carpentier-Edwards standard prosthesis implanted in 1984 and in place for 64 months. Score was 4 at radiography.

placement. As previously described, ${ }^{4}$ at the time of gross examination, the attachment of porcine cusps to the aortic wall at the commissure appeared intact, whereas it was the aortic wall that was completely detached from the stent post. At radiography, mineral deposits in the valve specimens were minimal or absent in 6 patients, thus proving that this commissural complication can occur solely and lead to valve dysfunction per se.

We share the current opinion that an excessive trimming of the aortic wall leads to weakening of the commissure and to an increased risk of dehiscence of the aortic wall from the stent post caused by mechanical stress. Nevertheless, commissural dehiscence, at a lower rate, occurred also in the Hancock II and Medtronic Intact bioprostheses, which do not undergo aortic wall trimming. Therefore other reasons might be applicable. Most of the porcine bioprostheses have a similar commissural suspension based on the suturing of the aortic wall to the fabric-covered stent. An infiltration of blood behind the commissure might create a hematoma, which, by means of progressive swelling, might detach the commissure, as in the case of the Xenotech prosthesis (Figure 3). Cuspal hematoma has been reported as a rare complication causing valve stenosis as a result of blood infiltration at the basal cusp suturing, accounting for hematoma dissection. ${ }^{18}$

The Biocor prosthesis has a pericardial shield tailored to cover the superior profile of the junction between stentfabric-aortic wall and sutured between the inner and the outer side of the stent, ${ }^{19}$ thus preventing this complication (Figure 5). Number and time of function of Biocor explants in our series of both aortic ${ }^{19}$ and mitral valve replacement, ${ }^{20}$ in which no commissural dehiscence occurred, was too short to confirm this hypothesis, and therefore pathologic studies on long-term explants are mandatory. However, it is fundamental to add to these considerations that (1) in both our studies ${ }^{19,20}$ freedoms from SVD were calculated, including also the echocardiographic results; (2) only 3
SVD cases were observed for the aortic valves and none for the mitral valves at 8-year follow-up; and (3) in no patient was a commissural dehiscence observed at 2-dimensional echocardiography.

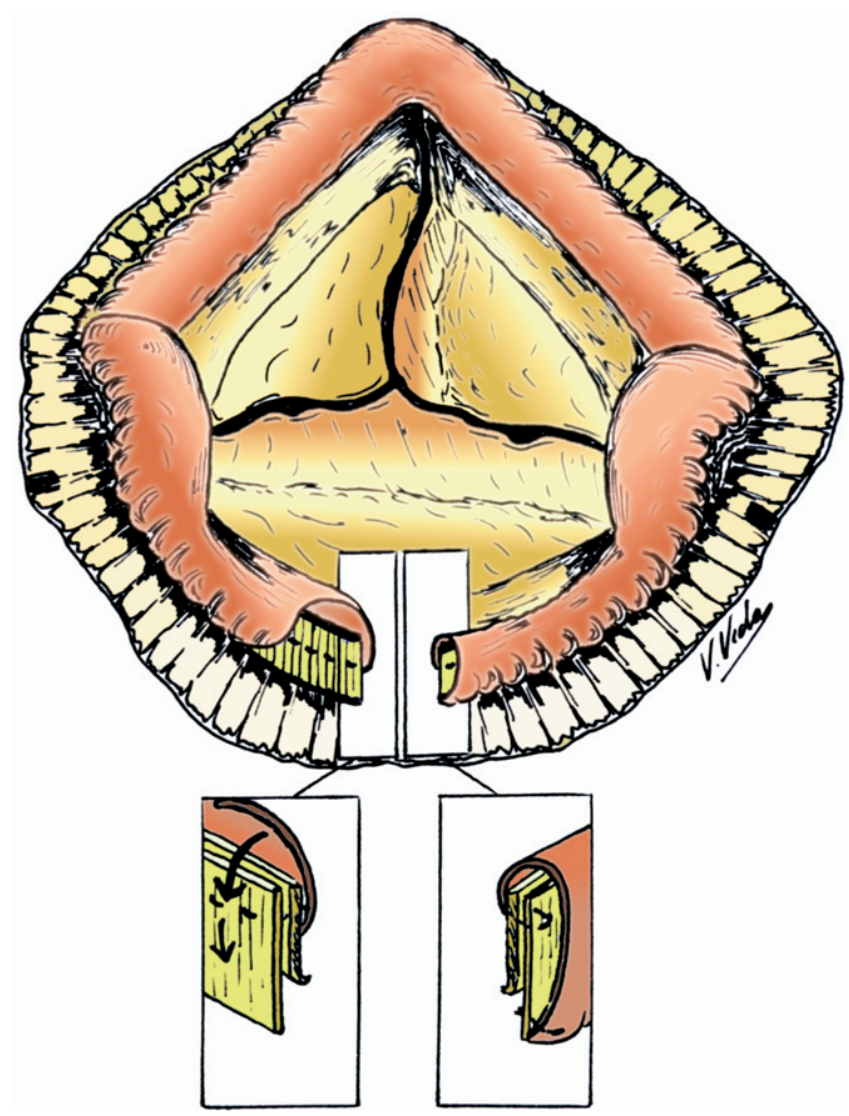

Figure 5. Drawing depicting a Biocor valve. Note that a pericardial sheet covers the superior profile of the stent to which the aortic wall and the fabric are sutured. 


\section{Conclusions}

Commissural dehiscence from the stent post in the porcine valves is a peculiar and uncommon cause of dysfunction occurring in $2.9 \%$ of explants. It was observed mainly in the mitral position, and it was responsible for valve incompetence severe enough to require a reoperation. In our experience, among various models, commissural dehiscence was observed earlier and more frequently in Carpentier-Edwards porcine valve explants. Manufacturing solutions, such as those introduced in the second-generation Biocor porcine prostheses, might prevent or reduce this complication.

We thank Mr Nicola Paccagnella for his assistance in preparing the figures and Mrs Chiara Carturan for editing the manuscript.

\section{References}

1. Jamieson WR, Burr LH, Janusz MT, Munro AI, Hayden RI, Miyagishima RT, et al. Carpentier-Edwards standard and supraannular porcine bioprostheses: comparison of technology. Ann Thorac Surg. 1999;67:10-7.

2. David TE, Ivanov J, Armstrong S, Feindel CM, Cohen G. Late results of heart valve replacement with the Hancock II bioprosthesis. J Thorac Cardiovasc Surg. 2001;121:268-77.

3. Rizzoli G, Bottio T, Thiene G, Toscano G, Casarotto D. Fifteen years durability of Hancock II porcine bioprostheses. J Thorac Cardiovasc Surg. 2003;126:66-74.

4. Nistal JF, Hurle A, Gutierrez JA, Mazorra F, Revuelta JM. Commissural dehiscence of Carpentier-Edwards mitral bioprostheses. Explant analysis and pathogenesis. J Thorac Cardiovasc Surg. 1995;110:688-96.

5. Gallucci V, Bortolotti U, Milano A, Valfre C, Mazzucco A, Thiene G. Isolated mitral valve replacement with the Hancock bioprosthesis: a 13-year appraisal. Ann Thorac Surg. 1984;38:571-8.

6. Jamieson WR, Lemieux MD, Sullivan JA, Munro AI, Metras J, Cartier PC. Medtronic intact porcine bioprosthesis: 10 years' experience. Ann Thorac Surg. 1998;66(suppl):S118-S121.

7. Bottio T, Thiene G, Pettenazzo E, Ius P, Bortolotti U, Rizzoli G, et al Hancock II bioprosthesis: a glance at the microscope in mid-long term explants. J Thorac Cardiovasc Surg. 2003;126:99-105.

8. Milano A, Bortolotti U, Talenti E, Valfrè C, Arbustini E, Valente M, et al. Calcific degeneration as the main cause of porcine bioprosthetic valve failure. Am J Cardiol. 1984;53:1066-70.
9. Bottio T, Rizzoli G, Valente M, Casarotto D, Thiene G. Cause of structural valve deterioration in porcine bioprostheses implanted for more than 15 years. In: Proceedings of the 1st Biennial Meeting of the Society for Heart Valve Disease; 2001; London, United Kingdom. p. 104.

10. Jamieson EWR, Marchand MA, Pelletier CL, Norton R, Pellerin M, Dubiel TW, et al. Structural valve deterioration in mitral replacement surgery: comparison of Carpentier-Edwards supra-annular porcine and Perimount pericardial bioprostheses. J Thorac Cardiovasc Surg. 1999; 118:297-304

11. Allard MF, Thompson CR, Baldelli RJ, McNab JS, Babul SA, Betts $\mathrm{JM}$, et al. Commissural region dehiscence from the stent post of Carpentier-Edwards bioprosthetic cardiac valves. Cardiovasc Pathol. 1995;4:155-62.

12. Kimura M, Iwakuma A, Morishige N, Nakamura K, Tachikawa Y, Shibano R, et al. Commissural dehiscence and pannus formation of porcine heart valve bioprostheses. Artif Organs. 2003;27:706-13.

13. Gudas VM, Jamieson WRE, Burr H, Janusz MT, Fradet GJ, Lichtenstein SV, et al. Carpentier-Edwards Supra-annular mitral porcine bioprosthesis: reassessment to 18 years. In: Proceedings of the 3rd Biennial Meeting of The Society for Heart Valve Disease; Vancouver, British Columbia, Canada; June 17-20, 2005. p. 97.

14. Barratt-Boyes BG, Jaffe WM, Whitlock RM. The Medtronic Intact porcine valve: ten-year clinical review. J Thorac Cardiovasc Surg. 1998; 116:1005-14

15. Ruel M, Kulikn A, Rubens FD, Bédard P, Masters RG, Pipe AL, et al. Late incidence and determinants of reoperation in patients with prosthetic heart valves. Eur J Cardiothorac Surg. 2004;25:364-70.

16. Rizzoli G, Mirone S, Ius P, Polesel E, Salvador L, Zussa C, et al. Fifteen year results of the Hancock II valve: a multicenter experience. J Thorac Cardiovasc Surg. 2006;132:602-9.

17. Naqvi TZ, Siegel RJ, Buchinder NA, Miroshnik S, Saedi G, Trento A, et al. Echocardiographic and pathologic features of explanted Hancock and Carpentier-Edwards bioprosthetic valves in the mitral position. Am J Cardiol. 1999;84:1422-7.

18. Thiene G, Bortolotti U, Talenti E, Guerra F, Valente M, Milano A, et al. Dissecting cuspal hematomas: a rare form of porcine bioprosthetic valve dysfunction. Arch Pathol Lab Med. 1987;111:964-7.

19. Bottio T, Rizzoli G, Thiene G, Nesseris G, Casarotto D, Gerosa G. Hemodynamic and clinical outcomes with the Biocor valve in the aortic position: an 8-year experience. J Thorac Cardiovasc Surg. 2004;127:1616-23.

20. Rizzoli G, Bottio T, Vida V, Nesseris G, Caprili L, Thiene G, et al. Intermediate results of isolated mitral valve replacement with a Biocor porcine valve. J Thorac Cardiovasc Surg. 2005;129:322-9. 